\title{
Adjusting Whitewater Recreation and Tourism to an Ageing Market.
}

\begin{abstract}
Adventure recreation and tourism now includes older participants. To take advantage of this growing market sector, tour operators need to know how they are affected by ageing. Here I use posts on a large but specialised social media site to provide relevant textual data, analysed using standard qualitative methods. Three main approaches are identified: maintaining skills and capabilities as long as possible, through training, warm-ups, and painkillers; adjusting to reduced capability, e.g. by paddling warmer and easier rivers and adopting easy-to-use equipment; and accepting reduced capability, by enjoying other aspects of white-water rivers, such as nature and social components.
\end{abstract}

\section{Management implications}

White-water tour operators catering to older clients should: pick sites that are clean, warm, and scenic; keep tours slow, safe, social, and comfortable; provide equipment, technical advice, and encouragement; run warm-up sessions, keep food and drinks accessible, shorten active hours per day, and allow time for recovery.

Keywords: adventure; river; kayak; raft; old; social

\section{Introduction}

Older individuals in developed nations can provide a valuable tourism market. Tourism enterprises need information on their ambitions, expectations, and limitations, compared to younger clientele (Bernini \& Cracolici, 2015; Chen \& Shoemaker, 2014; Huber et al., 2018; Kim et al., 2015). Recently, senior tourism has expanded to include adventure tourism (Patterson, 2019). Factors distinguishing older individuals who continue adventure activities, from those who abandon them, are therefore important in tourism marketing and management. Perceptions of older adventure tourists have received little previous attention. There are qualitative small-group studies, in various countries, of hikers, bikers, climbers, skiers and snowboarders, sea-kayakers, surfers, and divers, aged up to 80 (Buckley, 2018a,b; Gregory \& Dimmock 2019; Hickman et al., 2016; Wang \& Wang, 2017; Wheaton, 2017). This note analyses participant perceptions for a substantially larger group of older participants in whitewater kayaking, a subsector of adventure recreation and tourism.

\section{Methods}

Participant perceptions are examined though qualitative analysis of online posts, from a discussion thread in the group "Addicted to Whitewater", on the social media platform Facebook ${ }^{\circledR}$. This is a worldwide, moderated group, with 13,305 members, who publish photos, videos, information, queries, and recommendations, under their own names, with $\sim 250$ posts/month. The initial post in this thread, on March 28, 2019, asked how older members manage to stay active (Scruggs, 2019). In $<1$ week, it attracted 110 written comments by 82 individual respondents, and 260 emoji comments by a further 105 individuals: 187 individuals in all, $1.4 \%$ of the entire group membership. This is in the top $1 \%$ of response rates within this group. This group may include local recreation as well as tourism, but many posts in this thread refer to travelling to paddle, qualifying the participants as tourists. Judging from posts, group members include a wide range of skills and interests. 
All posts in the thread were copied to a textual dataset, with posters' full names still attached. Ages of posters were determined from statements by the respondents. Most were in their 50's and 60's, with at least four aged over 70. Genders of posters were determined from names, with no ambiguous cases. Only 8 of 82 were female. This reflects the age of the respondents: female representation in white-water adventure tourism is higher for younger age groups. Text was analysed using qualitative methods: deconstruction and basic coding of lowest-level identifiable concepts; reassembly into an efficient hierarchical tree of qualitative constructs; reinterpretation using axial coding to identify an underlying causative model; and illustration of higher-level constructs using selected quotations from the textual dataset. Coding relied on straightforward linguistic content, interpreted in the light of author experience. Experience in the activity examined, in this case white-water adventure tourism, assists in interpretation of online posts, but may reflect the analyst's cultural and personal context.

The author is 65 years old, male, Caucasian, Anglophone, and resident in Australia. Over past decades, he has been a guide, client, or safety boater in commercial white-water raft and kayak tours, and private expeditions, in a number of countries. His skill level in white-water kayaking was previously advanced intermediate, though now much reduced through age and chronic injuries. He has conducted previous research on various aspects of adventure tourism, including white-water kayaking, and including safety, communications, psychology, and ageing. He does not know any of the individuals posting in this particular thread, and has had no communication with any of them, but he is familiar with the issues raised.

\section{Results}

\subsection{Open coding}

A 3-tier open coding tree is summarised in Table 1. A total of 45 lowest-level concepts were recognised, grouped into 21 mid- and 3 high-level constructs. At the highest level, respondents proposed three approaches. The first was to maintain one's capability as long as possible. Subsidiary (mid-tier) approaches included long-term fitness and short-term technique. The second was to recognise and adapt to reduced capability. This included paddling easier rivers, changing to less demanding equipment, paying more attention to safety, and accepting advice and assistance from other kayakers. The third was to enjoy the river and activity despite reduced capability. This included enjoyment of the activity itself, natural surroundings, social context, and passing on knowledge to others.

\subsection{Axial coding}

The aim of axial coding was to identify how ageing clientele affects the white-water tourism industry. Four principal themes were identified: location, people, equipment, practice. All of these themes, and associated comments, resonate closely with the author's own experience. Under the location theme, participants mentioned travelling to paddle easier, cleaner, warmer, and more scenic rivers. Relevant phrases include: "keep exploring"; "scenic rivers"; "pretty creeks, warm weather"; "paddle easier runs"; and "play, play, play". Under the people theme, comments show that older tourists are no longer keen on solo activities. They want partners, for safety and friendship: "solid paddling partners"; "safety meetings"; "paddling friends"; "more social now". They were glad to act as mentors: "take somebody under your wing"; "giving back". Many wanted family opportunities: "taking my kids, watching them learn". 
Table 1. Open Coding Tree.

\begin{tabular}{|l|l|}
\hline High and mid tier constructs & Lowest tier concepts \\
\hline Maintain maximum capability & \\
\hline Train, stay fit & Strength, flexibility, yoga, cross-training \\
\hline Use technique & Skill not strength \\
\hline Get ready on the day & Hydration, stretches, warm-up \\
\hline Overcome pain & Painkillers, alcohol, coffee \\
\hline Maintain enthusiasm & Passion, addiction, aim high \\
\hline & \\
\hline Adjust to reduced capability & \\
\hline Humility & Overcome ego, stay humble \\
\hline Safety & Play safe, know own limits \\
\hline Backup & Paddle with competent partners \\
\hline Respect & Respect for more capable paddlers \\
\hline Advice & Allow others to advise you \\
\hline Equipment & Easier kayak, canoe, inflatable, raft; change paddle \\
\hline Downgrade & Paddle less difficult rapids (lower grades) \\
\hline Shorter & Paddle at “park-play" sites, single cf multi-day trips \\
\hline Warmth & Travel to sites with warm water and weather \\
\hline Novelty & Travel to new rivers \\
\hline & \\
\hline Enjoy despite lower capability & \\
\hline Fun & Fun, play, use every river feature \\
\hline Savour & Scenery, nature, pay attention, savour \\
\hline Teach & Teaching, handover, mentoring \\
\hline Advocacy & Political involvement in river conservation and access \\
\hline Share & Social, friends, family \\
\hline
\end{tabular}

The third theme includes equipment, technique and attitude. Comments included: "more comfortable boat"; "bigger, less surprising boat"; "an inflatable"; "a raft"; "bent-shaft paddles"; "technique and form"; "humility, no ego"; "stay humble". The fourth theme is about recognising one's limits and taking care of one's body, to maximise capability and enjoyment. Comments included: "take care of your body"; "warm up first"; "nutrition and hydration"; "don't overstretch yourself"; "let your body recover"; "your body will make you pay if you don't treat it right"; "know your limits and your skill level".

Despite all these restrictions and obstacles, the respondents in this thread remained highly motivated, with comments such as "addicted to rivers"; "every river a challenge"; and "never too old". The older clientele have maintained their enthusiasm, so they represent an excellent market for commercial adventure tourism. But they have reduced capabilities and different goals, so tour operators need to modify the locations, design, and operations of their tours, including equipment and guiding practices, to attract the older clientele. 


\section{Discussion}

All of these themes reflect a different attitude amongst older white-water tourists. Older clientele recognise that they no longer have their former skills and stamina. They rely on tour operators to take them on rivers within their reduced capabilities, and to provide comfort, logistic convenience, reliable and forgiving equipment, and ample safety support. They appreciate scenic beauty, and opportunities for friends and family, as well as white water.

Some of these concepts and constructs reflect findings reported in previous research. These include: maintaining capability as long as possible; lowering one's sights when forced to do so; increasing the emphasis on safety; recognising limitations; and surrendering leadership to the next generation (Buckley, 2018a,b). They also include: savouring the entire experience, not only the thrills (Hickman et al., 2016; Wheaton, 2017); and enjoying the social and family aspects, at a lower level of skill and risk. Contrary to previous findings, participants did not mention adrenalin-based euphoria (Buckley, 2018a), nor deny declining capabilities with age (Buckley, 2018b).

Two global-scale social and demographic trends suggest increasing significance for findings such as those reported here. The first is that the "boomer" generation in Western nations, which grew up without reliance on outdoor tour operators, is now ageing considerably. They still value adventure recreation experiences, but they now need assistance, providing a new market for these providers (Albayrak and Caber, 2018). Younger generations grew up with opportunities to purchase fully-guided tours, so they provide a parallel market, albeit with somewhat different motivations. This also applies in nations where commercial outdoor recreation is only a recent social trend, such as China (Buckley et al., 2014), and Middle Eastern nations (Buckley et al., 2019a). The second major trend is that the healthcare industry is increasingly recognising the value of nature-based experiences (Buckley et al., 2019b), including outdoor recreation and tourism (Buckley, 2019); and this value may be highest for older individuals with higher per capita healthcare costs.

\section{Conclusions}

From a research perspective, these findings are derived from white-water tourism, but can now be tested for many other adventure tourism activities. These findings are derived only from participants in Anglophone developed nations, and can now be tested in other cultural contexts with different social expectations and individual motivations for ageing individuals. The approach and methodology used here could also be applied across many groups, social media platforms, activities, tourism subsectors, and countries and cultures. For example, there are Facebook ${ }^{\circledR}$ groups for shopping tourism. This analysis used a passive approach, taking advantage of a question posed by a group member. Researchers can also pose questions themselves, as long as they can demonstrate credentials to the groups concerned.

Management implications are derived from each of the four key themes. For white-water tour operators to cater to older clientele, they should: (1) offer trips to countries, rivers, and river sections that are easier, cleaner, warmer, and more scenic; (2) run trips at a slower pace, with greater attention to comfort and safety, and greater social opportunities, including family options; (3) provide equipment appropriate to older participants, offer diplomatic advice on technique, and ensuring that older clients maintain a relaxed and positive attitude; and (4) provide snacks and drinks all day as well as at camp; run warm-up sessions at the beginning of each day; and shorten the number of active hours each day, to allow more recovery time. 


\section{References}

Albayrak, T., \& Caber, M. (2018). A motivation-based segmentation of holiday tourists participating in white-water rafting. Journal of Destination Marketing \& Management, 9, 6471.

Bernini, C., \& Cracolici, M.F. (2015). Demographic change, tourism expenditure and life cycle behaviour. Tourism Management, 47, 191-205.

Buckley, R.C. (2018a). Nature sports, health and ageing: the value of euphoria. Annals of Leisure Research, 1-18. doi:10.1080/11745398.2018.1483734

Buckley, R.C. (2108b). Aging adventure athletes assess achievements and alter aspirations to maintain self-esteem. Frontiers in Psychology, 9, 225.

Buckley, R.C. (2019). Therapeutic mental health effects perceived by outdoor tourists: A large-scale, multi-decade, qualitative analysis. Annals of Tourism Research, 77, 164-167.

Buckley, R., McDonald, K., Duan, L., Sun, L., \& Chen, L. X. (2014). Chinese model for mass adventure tourism. Tourism Management, 44, 5-13.

Buckley, R., Shekari, F., Mohammadi, Z., Azizi, F., \& Ziaee, M. (2019a). World Heritage tourism triggers urban-rural reverse migration and social change. Journal of Travel Research, 0047287519853048.

Buckley, R., Brough, P., Hague, L., Chauvenet, A., Fleming, C., Roche, E., et al. (2019b). Economic value of protected areas via visitor mental health. Nature Communications, 10 , 5005 .

Chen, S.C., \& Shoemaker, S. (2014). Age and cohort effects: The American senior tourism market. Annals of Tourism Research, 48, 58-75.

Gregory, S.F., \& Dimmock, K. (2019). Alive and kicking: the benefits of scuba diving leisure for older Australian women. Annals of Leisure Research, 1-25.

doi:10.1080/11745398.2019.1605914

Hickman, M., Stokes, P., Gammon, S., Beard, C., \& Inkster, A. (2016). Moments like diamonds in space: savoring the ageing process through positive engagement with adventure sports. Annals of Leisure Research, 21, 612-630.

Huber, D., Milne, S., \& Hyde, K. F. (2018). Constraints and facilitators for senior tourism. Tourism Management Perspectives, 27, 55-67.

Kim, H., Woo, E., \& Uysal, M. (2015). Tourism experience and quality of life among elderly tourists. Tourism Management, 46, 465-476.

Patterson, I. (2018). Different travel markets: adventure tourism and the older traveller. In Patterson, I., Tourism and Leisure Behaviour in an Ageing World, 135-155. CABI, Wallingford. 
Scruggs, M. (2019). Post on "Addicted to Whitewater." https://www.facebook.com/groups/1430295047247578/

Wang, P.Y. \& Wang, S.H. (2017). Motivations of adventure recreation pioneers - a study of Taiwanese white-water kayaking pioneers. Annals of Leisure Research, 21, 592-604.

Wheaton, B. (2017). Surfing through the life-course: silver surfers' negotiation of ageing. Annals of Leisure Research, 20, 96-116. 